\title{
CARGA MÁXIMA EN FUNCIÓN DE LA POROSIDAD EN PIEZAS CERÁMICAS ELÉCTRICAS
}

\author{
Idalia Gómez ${ }^{1}$ y José Luis Cavazos ${ }^{2}$ * \\ ${ }^{1}$ Universidad Autónoma de Nuevo León, Facultad de Ciencias Químicas, Laboratorio de Materiales 1. \\ ${ }^{2}$ Universidad Autónoma de Nuevo León, Facultad de Ingeniería Mecánica y Eléctrica. \\ *corresponding author:jose.cavazosgc@uanl.edu.mx
}

\section{RESUMEN}

La categoría general de cerámicas eléctricas incluye una amplia gama de composiciones y estructuras. La mayoría de estos cerámicos se utilizan como aislantes eléctricos. En aplicaciones de alta frecuencia y baja pérdida dieléctrica generalmente se utilizan cerámicos de forsferita, steatita y alúmina. El presente estudio se realizó sobre cerámicas eléctricas utilizadas como cortocircuitos en transformadores de energía eléctrica, por lo que una de sus características es la de tener alta resistencia mecánica sin afectar sus propiedades eléctricas. Estas piezas cerámicas tienen en la parte central un barreno en donde se le coloca piedra cerámica cementante para fijarlas en los transformadores. Se analizaron piezas cerámicas con temperaturas de quemado iguales pero con colocación de piedra cementante en tres posiciones diferentes: sin piedra, con piedra y con piedra a $1 \mathrm{~cm}$ del borde, con la finalidad de caracterizar la res istencia mecánica en ensayos de flexión en función de la colocación de la piedra cementante. En función de lo anterior, las piezas fueron sometidas a ensayos mecánicos de flexión y posteriormente se analizó la zona de fractura mediante microscopía óptica, analizador de imágenes y microscopía electrónica de barrido, encontrándose en las cerámicas con piedra perfiles de porosidad inversos a los que presentados en cerámicas sin piedra, lo cual influyó en la respuesta mecánica observada.

Palabras clave: cerámicas eléctricas, ensayos de flexión, porosidad

\begin{abstract}
The general category of electric ceramics includes a wide range of compositions and structures. Electric insulators are the main application of these ceramic materials. Forsferite, steatite and alumin um ceramics are used in applications of high frequency and low dielectric loss. The present study is related to an application of electric ceramics in energy transformers as short circuits. One of their characteristics is a high mechanical resistance, which should not affect their electrical properties. These ceramic pieces have, at the center of their bodies, one hole where cement stone ceramic is put to fix these in the transformers. In order to know how the cement stone ceramic microstructure will affect the mechanical resistance, ceramic short circuits with the same sintering conditions temperature, but with different placing of stone were analyzed; three different positions were studied, without stone, with stone and stone placed at one centimeter of the edge. Mechanical test to flexion were carried out in different samples and their failure zone was analyzed using optic microscope, image analyzer and scanning electron microscope. In ceramics with stone, an inverse concentration of porosity profiles were founded in relation to the profile showed by ceramic without stone, that characteristic is the main responsible of the mechanical response observed.
\end{abstract}

Key words: ceramic electrics, flexion tests, porosity. 


\section{INTRODUCCIÓN}

Se define a un cerámico como aquel material compuesto de uno o varios óxidos metálicos y no metálicos, que se caracteriza principalmente por su baja conductividad térmica y eléctrica, así como fragilidad mecánica [1,2].

Los cerámicos son utilizados en aplicaciones tecnológicas en una gran variedad de formas: monolíticos, polvos finos y fibras, entre otros. Cada uno de estos pueden ser monocristalinos o policristalinos y pueden incluir una o mas fases. El número, tipo y distribución física de las fases se determinan por su equilibrio y la historia térmica del material $[2,3]$.

Muchas cerámicas se basan en la arcilla, a la cual se le añade un material más grueso como el cuarzo, y un material fundente como el feldespato. Los feldespatos son un grupo de minerales que comprende al $(\mathrm{K}, \mathrm{N})_{2} \mathrm{O} \cdot \mathrm{Al}_{2} \mathrm{O}_{3} \cdot 6 \mathrm{SiO}_{2}$. En el diagrama termodinámico de fases ternario $\mathrm{Al}_{2} \mathrm{O}_{3}-\mathrm{SiO}_{2}-\mathrm{K}_{2} \mathrm{O}$, se puede ubicar a las porcelanas eléctricas en los porcentajes de concentraciones de:

\section{$42.47-44.79 \%$ de $\mathrm{Al}_{2} \mathrm{O}_{3}$}

$$
47.24-45.23 \% \text { de } \mathrm{SiO} 2
$$

$$
10.27 \text { - } 9.96 \% \text { de } \mathrm{K}_{2} \mathrm{O}
$$

Los aislantes eléctricos deben tener poca porosidad, por eso las arcillas están completamente vitrificadas, como la porcelana o el vidrio, para su uso como aislantes eléctricos en aplicaciones de alto voltaje [1].

Además de cumplir con ciertas características de propiedades eléctrica s aislantes, las piezas ceramicas deben de cumplir con resistencia mecánica a la flexión con la finalidad de ser utilizadas en la industria eléctrica. El método para determinar el comportamiento de los materiales sometidos a la carga de la viga simple, es el ensayo de flexion. Con algunos materiales, también se denomina ensayo de la viga transversal. La muestra o probeta está soportada por dos cuchillas como viga simple y la carga se aplica en su punto medio. El esfuerzo máximo de la probeta y la deformación máxima se calculan en incrementos de carga. Los resultados se grafican en un diagrama de esfuerzo deformación y el esfuerzo máximo de la probeta es la resistencia a la flexión.
La falla mecánica de materiales cerámicos se produce principalmente debido a los defectos estructurales. Las principales causas de la fractura en cerámicas policristalinas se deben buscar en las grietas, las cuales normalmente se producen durante los procesos de conformación y acabado, así como en los poros o inclusiones y en los granos grandes formados durante el proceso de cocción de las cerámicas, los cuales actúan como concentradores de esfuerzos, fragilizando al material.

El objetivo de este trabajo es analizar el comportamiento de piezas cerámicas empleadas como aislantes en transformadores eléctricos. El estudio contempla el análisis microestructural de la zona de fractura de piezas ensayadas a flexión, con el fin de relacionar la microestructura con la resistencia mecánica observada de las mismas. Se hace uso, además de una máquina universal para ensayos mecánicos para realizar el ensayo de flexión, de técnicas de análisis de microscopía óptica y electrónica.

\section{PROCEDIMIENTO EXPERIMENTAL}

Se identificaron quince piezas cerámicas aislantes, las cuales tienen un barreno en su zona central con piedra cementante para fijarlas posteriormente en los transformadores eléctricos (ver figura 1). Con la finalidad de analizar el efecto que tiene la colocación de dicha piedra cementante se realizó el estudio en base a la colocación de ésta en la zona del barreno, y se clasificaron como se muestra en la Tabla 1.
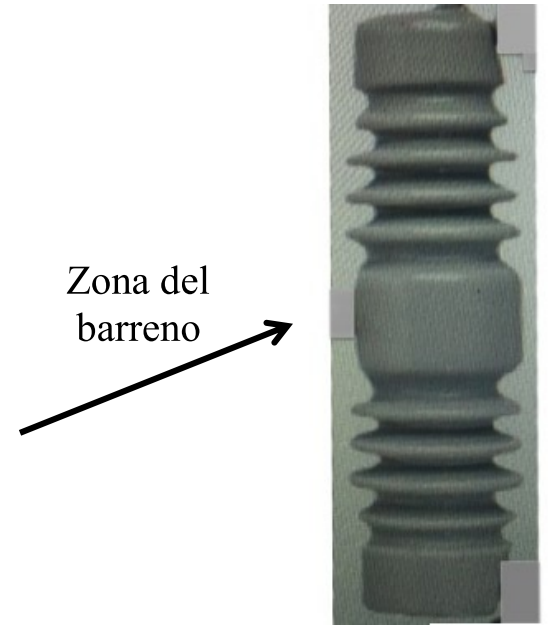

Fig. 1 Fotografía del tipo de piezas cerámicas eléctricas analizadas. 
Tabla 1

Clasificación de las muestras

\begin{tabular}{|c|c|}
\hline identificación & característica \\
\hline A & sin piedra \\
\hline B & con piedra \\
\hline C & piedra a 1 cm del borde \\
\hline
\end{tabular}

Para la realización de los ensayos mecánicos de flexión se utilizó una máquina universal marca Tinius Olsen aplicándose una rapidez de desplazamiento de $8.47 \times 10^{-2} \mathrm{~mm} / \mathrm{s}$, a una temperatura de $22^{\circ} \mathrm{C}$ y $74 \%$ de humedad relativa en el ambiente. El ensayo se realizó en la zona central, que es la ubicación geométrica del barreno en las piezas cerámicas eléctricas.

Posteriormente, en piezas cerámicas fracturadas tomadas al azar, se les realizó un corte de manera longitudinal sobre la zona del barreno para realizar un análisis petrografíco y comparar las muestras. Para cortar las piezas se utilizó un disco de diamante y para el desbaste de las piezas se utilizaron lijas de carburo de silicio 50, 100, 280 y 400 , para el pulido se utilizaron lijas 800 , 1200 y paño. Las piezas ya preparadas para su análisis petrografíco fueron analizadas mediante el uso de microscopía óptica a 100 aumentos, (Microscopio óptico Olympus con software de análisis de imagen). El análisis por microscopía óptica permitió observar una diferencia en áreas de porosidad por lo que se utilizó un analizador de imágenes para comparar de manera cuantitativa los porcentajes de porosidad en seis zonas analizadas partiendo de la zona de piedra hacia adentro de la pieza como se muestra en la Tabla 2. El mismo análisis se practicó sobre otras muestras con las mismas dimensiones que las estudiadas anteriormente pero sin piedra.
Tabla 2

Zonas analizadas

\begin{tabular}{|c|c|}
\hline zona & Característica \\
\hline 1 & Sobre el esmalte \\
\hline 2 & a $3 \mathrm{~mm}$ del esmalte \\
\hline 3 & a $6 \mathrm{~mm}$ del esmalte \\
\hline 4 & a $1 \mathrm{~cm}$ del esmalte \\
\hline 5 & a $1.5 \mathrm{~cm}$ del esmalte \\
\hline 6 & a $2 \mathrm{~cm}$ del esmalte \\
\hline
\end{tabular}

Posteriormente se cortaron las zonas de inicio de fractura para realizar un análisis mas exhaustivo mediante microscopía electrónica de barrido en el modo de electrones secundarios, utilizando un Microscopio Electrónico de Barrido JSM-6510LV.

\section{RESULTADOS Y DISCUSIóN}

La superficie de fractura mostrada en las piezas cerámicas estudiadas tienen la característica propia de una fractura frágil, tal y como se observa en la micrografía de la figura 2 .

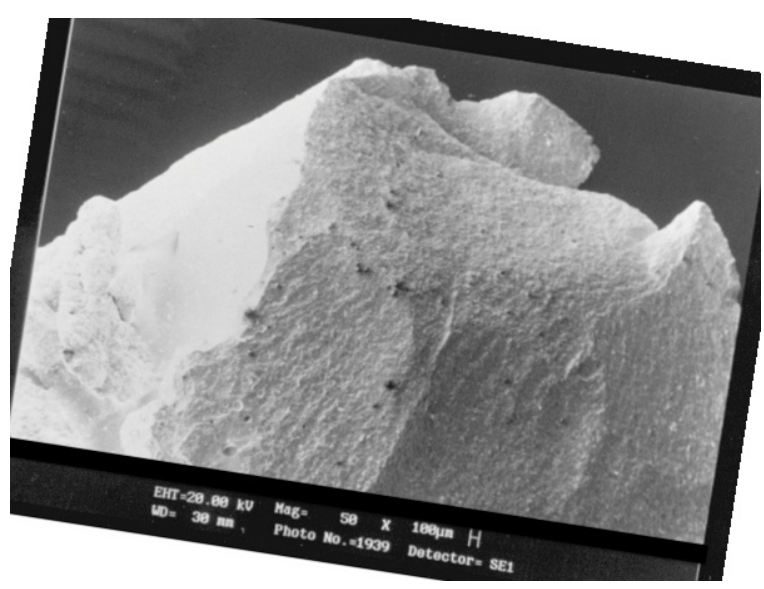

Fig. 2 Fotografía en zona de fractura de una muestra analizada. 
En la Tabla 3 se muestran los resultados de los ensayos mecánicos de flexión obtenidos; en estos se denota una diferencia de la resistencia mecánica en función de la colocación de la piedra cementante, lo cual se representó gráficamente en la figura 3 .

Tabla 3

Carga máxima de las muestras

\begin{tabular}{|c|c|c|}
\hline muestra & $\begin{array}{c}\text { Carga Máxima } \\
(\mathrm{Lb})\end{array}$ & $\begin{array}{c}\text { Desviación estándar } \\
(\mathrm{Lb})\end{array}$ \\
\hline A & 3300 & 164.9 \\
\hline B & 2645 & 202.9 \\
\hline C & 2940 & 88.4 \\
\hline
\end{tabular}

La resistencia mecánica mostrada por las piezas estudiadas en sus tres identificaciones, denotan de manera macroscópica un efecto provocado por la colocación de la piedra como se observa en el gráfico de resistencia mecánica de la figura 3; al realizar un análisis de imagen de las microestructuras de éstas se encontró un porcentaje de porosidad mas alto en la zona de interfase entre la piedra, el esmalte y el cuerpo de la pieza, que hacia adentro de la pieza, tal y como lo muestra el gráfico de porcentaje de porosidad presentado en la figura 4, contrario a lo presentado por la pieza identificada como A, en donde el porcentaje en porosidad sigue un comportamiento polinomial de grado 2 conforme aumenta la distancia del borde. El perfil de porosidad presentado en la pieza $A$ es característico de una sinterización producida por transferencia de calor homogénea convencional (de fuera hacia adentro) contrario a lo presentado por las piezas estudiadas (B y C) las cuales presentan un perfil de porosidad mayor del centro hacia fuera, lo cual es indicativo de que la piedra afecta de manera directa la transferencia de calor en la pieza, en el proceso de sinterización, bajo el cual son sometidas dichas piezas cerámicas eléctricas en su proceso de conformado; por otro lado, se observó una heterogeneidad respecto al perfil de porosidad como se denota en la figura 5 , una zona mucho mas porosa en la zona del esmalte, lo cual señala heterogeneidad en el proceso de sinterizado.

En la literatura se indica [5] que cuando la tensión alrededor de un poro alcanza un valor crítico, se provoca el inicio de grieta, la cual se propaga rápidamente al no disponer de procesos o mecanismos que absorban energía, tal y como si lo muestran los metales dúctiles durante la deformación. En las cerámicas, debido a los enlaces iónicos o covalentes de sus estructuras cristalinas, no son propicios al deslizamiento ni a la deformación por maclado; de esta manera, una vez iniciada la grieta, ésta continúa su crecimiento hasta provocar la rotura. De ahí que los poros, al igual que las inclusiones, afectan la resistencia mecánica del material. En las cerámicas, el tamaño y la fracción de volumen de poros son factores importantes que afectan grandemente a su resistencia mecánica.

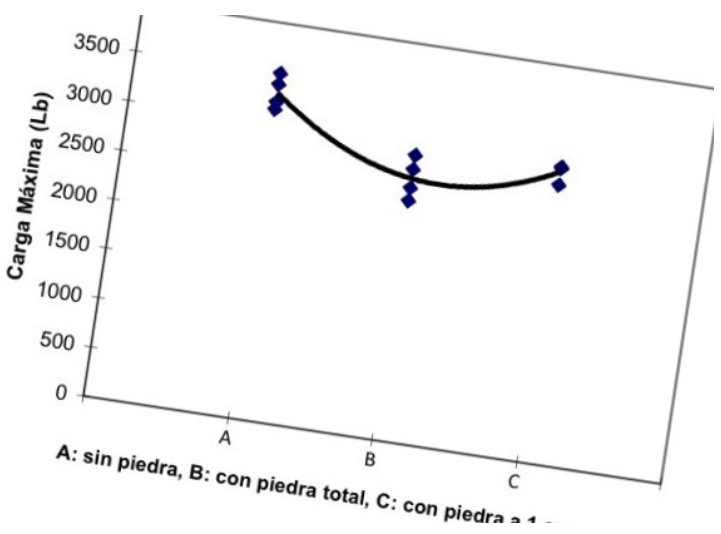

Fig. 3 Gráfico de la carga máxima soportada en piezas de cerámica analizadas.

\section{Porosidad en piezas cerámicas eléctricas}

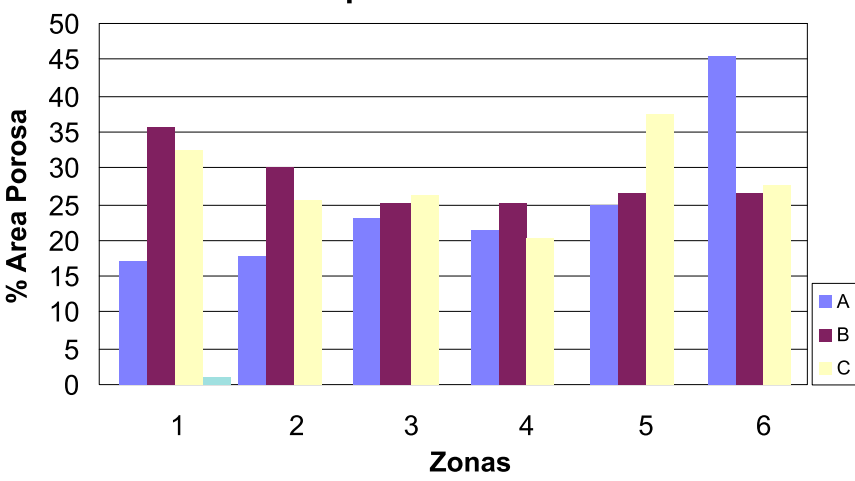

Fig. 4 Gráfico de barras del porcentaje de área porosa. 


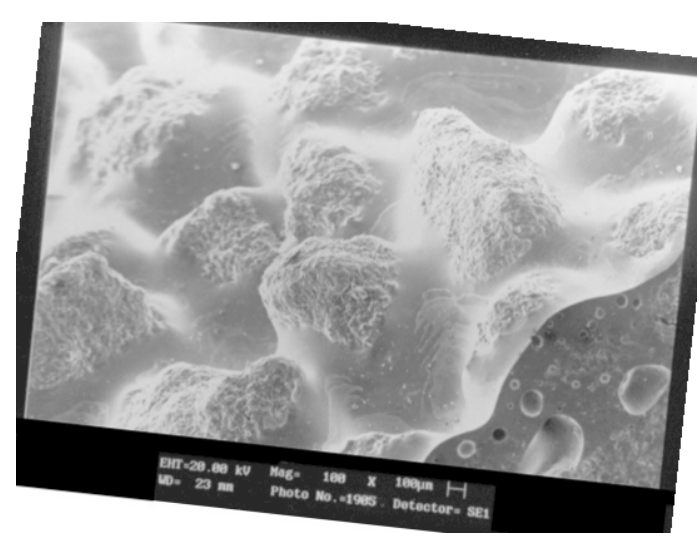

Fig. 5 Micrografía en microscopía electrónica de barrido de una muestra con piedra cementante.

De acuerdo a lo que reporta Kingery [1] respecto a que el mayor efecto de la estructura en la mayoría de los cerámicos es el resultado de la porosidad, ya que los poros disminuyen el área de la sección transversal sobre el cual se aplica la carga pero también actúan como concentradores de esfuerzo y que experimentalmente se ha encontrado que la resistencia de cerámicas porosas disminuye en una relación exponencial con la porosidad, se explica la relación entre la resistencia y el porcentaje de porosidad encontrado en las piezas analizadas.

Así mismo, se determinó que los inicios de fractura se marcan en zonas de porosidad alargados provocando líneas de grieta siendo éstas las zonas de menor resistencia mecánica. Por lo que resulta ilustrativo el observar las porosidades presentes en dos zonas analizadas de manera comparativa como se muestra en las figuras 6 y 7 .

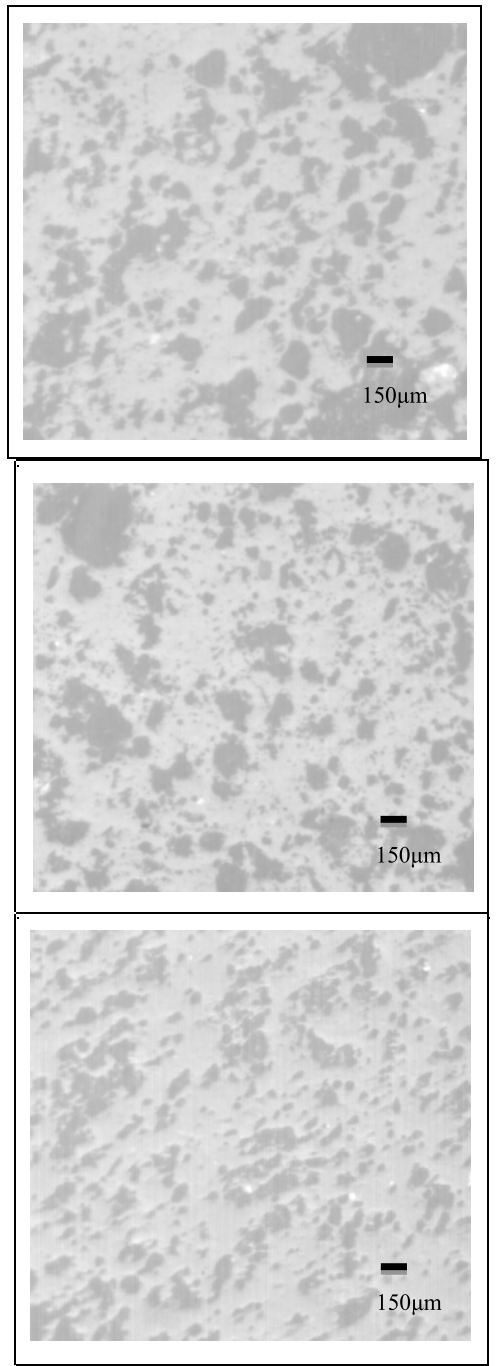

B1

C1

A1

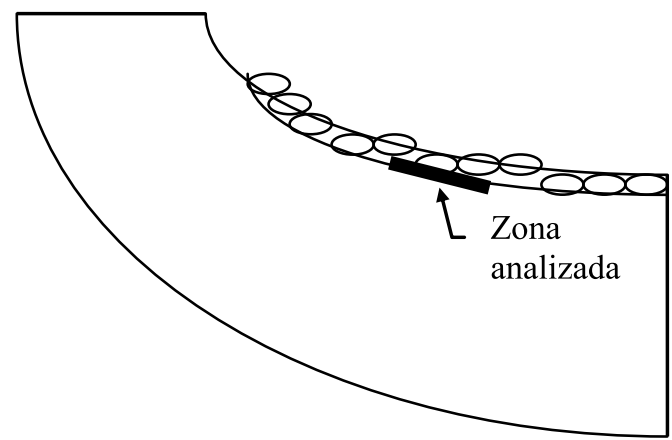

Fig. 6 Diagrama de la zona continua al esmalte de muestras analizadas con piedra cementante, B1 y

$\mathrm{C} 1$, comparadas con la muestra $\mathrm{A} 1$, quien no tiene piedra cementante. 

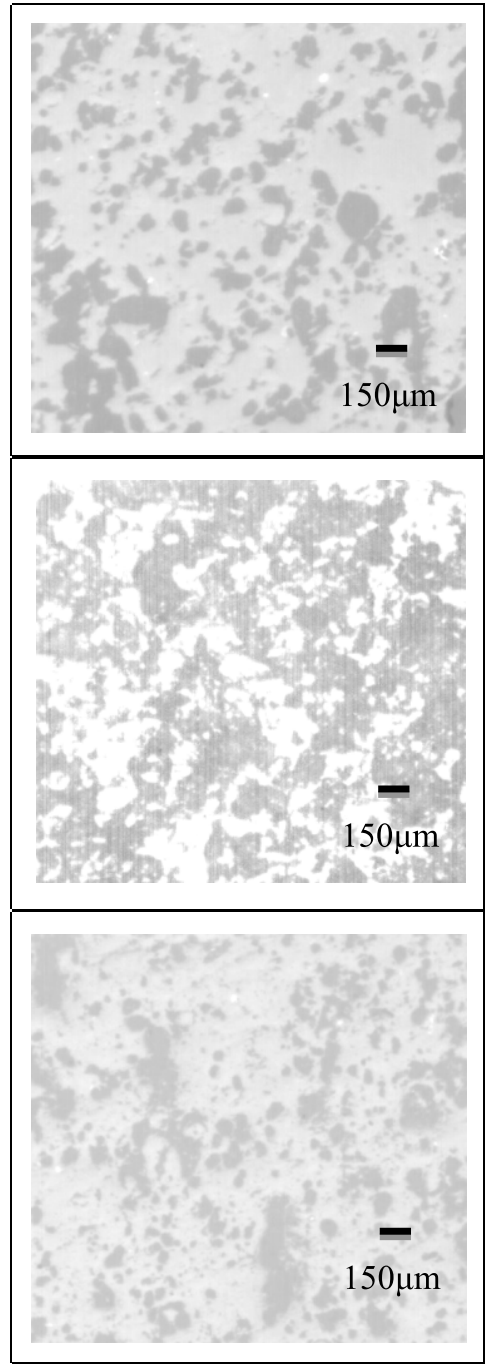

B6 C6

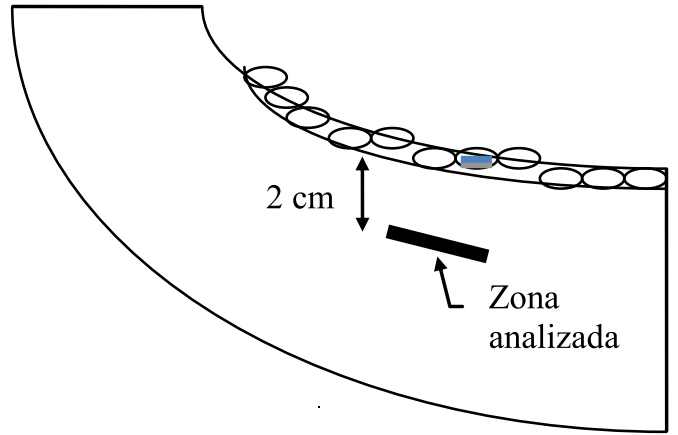

Fig. 7 Diagrama de la zona a $3 \mathrm{~cm}$ del esmalte, micrografías de muestras analizadas con piedra cementante, B6 y C6, comparadas con una muestra sin piedra cementante A6.

\section{CONCLUSIONES}

Los resultados de los ensayos mecánicos de flexión realizados a las piezas cerámicas eléctricas, permiten concluir que la resistencia mecánica en las piezas cerámicas estudiadas está en función de la colocación de la piedra cementante. La cual influye en la generación de porosidad en el cuerpo de la pieza cerámica, siendo éstos sitios de nucleación de grietas par llevar a la fractura la pieza. Esto es debido a que la piedra cementante interviene de manera directa como barrera en la transferencia de calor en la pieza en el proceso de sinterizado, provocando con ello un perfil de porosidad en detrimento de la resistencia mecánica.

\section{REFERENCIAS}

1. La Ciencia e Ingeniería de los Materiales, Donald R. Askeland, Grupo Editorial Iberoamérica, 1987.

2. Physical Ceramics, Yet-Ming Chiang, Dunbar Birnie III and W. David Kingery, John Wiley \& Sons, 1997.

3. Ceramic Microestructures, William E. Lee and W. Mark Rainforth, Capman \& Hall, First Edition, 1994.

4. Introduction to Ceramics, W. D. Kingery, H.K. Bowen and D.R. Uhlmann, John Wiley \& Sons, 1976. 